\title{
Notas sobre a questão das rimas na tradução do Orlando Furioso
}

Pedro Garcez Ghirardi

É sabido que traduzir poetas clássicos é defrontar-se muitas vezes com o problema da transposição da rima. Isto é o que ocorre no Orlando Furioso de Ariosto. Construído em oitavas de decassílabos (ou hendecassílabos, pelo cômputo italiano), os versos de cada estrofe do poema se dispõem em rimas alternadas (os seis primeiros) e emparelhadas (os dois últimos).

A construção em oitavas, que será seguida por outros poetas, como Camões e Tasso, é fundamental no Orlando Furioso. Como procurei dizer na "Introdução" à minha tradução (Ludovico Ariosto, Orlando Furioso, Ateliê, 2002), a regularidade fundamental dessa construção da estrofe faz contraponto ao transbordamento fantástico das aventuras cantadas e permite, muitas vezes, desvios que tornam variado o ritmo do poema. Isso tem como efeito reproduzir, no plano da expressão, o permanente diálogo entre "razão" e "loucura", diálogo que, como também procurei expor, é tema central do poema.

Cabe ao tradutor, portanto, tentar preservar essa construção da oitava, com todas as suas peculiaridades. Mas isto impõe, entre muitos problemas, o da transposição das rimas, que exige no Orlando Furioso atenção particular. Pois é sabido que este é um dos pontos em que a arte de Ariosto se revela magistral. 
Não é possível agora tratar extensamente dos problemas que resultam da tentativa de encontrar em nossa língua soluções que possam ajudar o leitor a perceber algo da riqueza do original italiano. Para não ir muito longe, aqui me limitarei a dar poucos exemplos de dificuldades encontradas e de traduções propostas.

Tomemos, por exemplo, o episódio em que o velho Atlante dá conselhos a Rogério, jovem guerreiro que criou como filho. $\bigcirc$ jovem, que tinha futuro promissor, a certa altura se apaixona pela feiticeira Alcina, a quem fica inteiramente sujeito. Quando Atlante o encontra, Rogério havia trocado as armas guerreiras pelo colar e pelos braceletes dados pela amada. Então o velho o repreende, com amarga ironia, dizendo que o rapaz começara bem e que assim logo chegaria a ser grande herói, como Júlio César, Alexandre, ou Cipião. Os versos, em italiano, são estes:

Questo è ben veramente alto principio onde si può sperar che tu sia presto a farti un Alessandro, un Iulio, un Scipio! Chi potea, ohimè, di te mai creder questo che ti facessi d'Alcina mancipio? E perché ognun lo veggia manifesto al collo ed alle braccia hai la catena con che ella a voglia sua preso ti mena.

Que significa, neste caso, buscar solução correspondente ao original? À primeira vista poderíamos pensar, por exemplo, numa proposta que partisse do nome 'Cipião' (Scipio), que terá de ser mencionado. Assim chegaríamos a rimas pertinentes, como 'escravidão' (mancipio) ou 'elevação' (alto). Estaria resolvido o problema? Acho que não. Parafraseando Drummond, 'seria uma rima não seria uma solução'. Isto porque o original aqui envolve 
rimas surpreendentes, raras, ao passo que em português as rimas em '-ão', como se sabe, são das mais comuns.

Era necessário, portanto, buscar também em nossa língua rimas incomuns. Isso levou a tomar como base não o nome de 'Cipião', mas o nome de 'Júlio' (César), também inevitável. A escolha acarretaria a necessidade de rimas em '-úlio', muito raras em português. $O$ discurso de Atlante ficou, então, assim traduzido:

É dos mais altos teu começo! Emule-o

Quem quiser, como tu, chegar depressa

A ser Cipião, ou Alexandre, ou Júlio!

Quem pode crer, oh, dor!, que isto aconteça,

Que de Alcina sucumbas ao acúleo?

E por que a servidão mais apareça,

Tens no pescoço e braços a cadeia

Com que ela a seu alvitre te meneia.

Exemplo semelhante da mestria de Ariosto no jogo de rimas e da dificuldade de traduzi-lo, é o que se encontra no canto VIII, 70. $O$ poeta havia descrito o exército de Carlos Magno cercado pelos invasores, que começavam a incendiar as muralhas de $\mathrm{Pa}$ ris. Ameaçado, o imperador recorreu à força da oração. E diz o poeta que Deus lhe ouviu a prece, fazendo cair uma chuva torrencial. Salva-se a cidade e o imperador reconhece que as forças humanas nada podem sem ajuda celeste. $\bigcirc$ original é este:

II Sommo Creator gli occhi rivolse

al giusto lamentar del vecchio Carlo,

e con subita pioggia il fuoco tolse, 
GHIRARDI, Pedro Garcez. Notas sobre a questão das rimas...

né forse uman saper potea smorzarlo.

Savio chiunque a Dio sempre si volse

ch'altri non potè mai meglio aiutarlo.

Ben dal devoto re fu conosciuto

che si salvò per lo divino aiuto.

Deixemos outros aspectos da tradução desta oitava (como o adjetivo savio, que merece atenção pelo contínuo diálogo do poema entre razão e loucura) e fiquemos uma vez mais no caso da rima. Aqui Ariosto volta a trabalhar com rimas incomuns. A dificuldade maior está no caso do nome Carlo, posto no fim do verso, o que realça a importância da figura do imperador, como ponto culminante da hierarquia da Cristandade. Ora, em português não há rimas para 'Carlos'. Que fazer? Tirar o nome da posição final? Isto seria fazer perder o importante realce que a posição na oitava dá a esse nome. Substituí-lo por equivalentes, como 'imperador'? A vantagem seria a abertura de um horizonte de termos pertinentes para a estrofe ('Criador', por exemplo). Entretanto, mais uma vez, seria a tentação de optar pelas rimas fáceis, mas comuns, não equivalentes, portanto, à criação original.

A solução procurada levou em conta que o imperador é conhecido como Carlos Magno. Aparentemente, isso pouco ou nada resolveria, pois continuaríamos sem saída. Entretanto, é preciso lembrar que Camões apresenta justamente um caso de rima entre "Magno" e "estranho" (Os Lusíadas, IV, 32). Com este precedente camoniano, foi possível manter a referência a Carlos no final do verso e propor a seguinte tradução para aquela oitava:

O sumo Criador os olhos volve

Ao justo lamentar de Carlos Magno;

Extingue ao fogo a chuva e a terra encobre 
(Não é dado ao mortal poder tamanho).

Sábio é quem seu cuidado a Deus devolve:

Terá melhor amparo que o de estranho.

Ao pio imperador o caso ensina

Que deve a salvação à mão divina.

Nesse mesmo canto, pouco adiante, achamos outro exemplo curioso de rima, que exige cuidado especial na tradução, a chamada "rima all'occhio", ou seja, rima visual, mais que sonora. É a que encontramos no canto VIII, 82. Orlando, num pesadelo, aflige-se com a visão de sua amada Angélica que desaparece num vendaval. $\bigcirc$ original diz assim:

Intanto l'infelice (e non sa come)

perde la donna sua per l'aer fosco

onde di qua e di là del suo bel nome

fa risonare ogni campagna e bosco.

E mentre dice indarno - Misero me!

Chi ha cangiata mia dolcezza in tosco? -

ode la donna sua che gli domanda,

piangendo, aiuto, e se gli raccomanda.

Nesta oitava, o verso 5 se resolve em uma rima visual, "all'occhio". "Misero" e "me" são, em italiano, duas palavras, cada qual com sua própria tonicidade. Correspondem a "ai de mim!". Entretanto, aqui, são tomadas como unidade visual ("miserome"), que cria a ilusão da rima perfeita com "come" (verso 1) e "nome" (verso 5). A tradução proposta, em português, procurou preservar esta característica. É a seguinte (grifei aqui a ocorrência): 
GHIRARDI, Pedro Garcez. Notas sobre a questão das rimas...

E vê o mísero a dama que se some (Como, não sabe) na borrasca escura:

Então, cá e lá, sai a gritar-lhe o nome

Por veredas do campo e da espessura.

- Infeliz! - vai gritando, eu aflijo-me.

Pois quem mudou em fel minha doçura?

Logo escuta, chorosa, sua dama

Que pede auxílio e que por ele clama.

Enfim, um último exemplo. Neste a dificuldade é talvez ainda maior, pois a rima implica em trocadilho. $\bigcirc$ caso é freqüente em Ariosto e é dos que maiores desafios impõem ao tradutor. Lembro o final do episódio da taça mágica (canto XLIII, 44), que mais tarde inspirou, aliás, um conto de La Fontaine. Nesse episódio, Rinaldo é convidado a servir-se de uma taça extraordinária. O homem que a leva aos lábios e consegue beber é feliz no amor, pois tem mulher fiel; se tentar beber e derramar o vinho, estará sendo traído. Rinaldo recusa-se a fazer a experiência e o dono da taça o elogia por isso, dizendo que ele foi o único homem sensato dos muitos que já encontrou. $\bigcirc$ elogio está nestes dois últimos versos da oitava:

Tu fra infiniti sol sei stato saggio,

Che far negasti il periglioso saggio.

Aqui Ariosto cria, nas rimas, um trocadilho entre dois sentidos da palavra italiana saggio: "sábio" e "experiência". A dificuldade está em encontrar, na transposição, algum equivalente de duplo sentido que permita um trocadilho sem alterar o sentido do original. A tradução proposta foi esta: 
Só tu, que não que a queres nem a provas,

Entre mil, de ser sábio deste provas.

Os exemplos poderiam continuar, pois não há oitava do Orlando Furioso que não apresente alguma questão de grande interesse para a discussão, seja no tocante à rima seja a outros aspectos. Mas espero que o que ficou dito seja suficiente para dar alguma idéia da riqueza do original, das dificuldades da tradução e, principalmente, para animar alguns à leitura dessa obra-prima da literatura do Renascimento.

\section{SOBRE O TRADUTOR}

Pedro Garcez Ghirardi, titular de Literatura Italiana na USP, foi tradutor juramentado de Italiano e Inglês e trabalha há quase trinta anos como professor de Literatura e de Tradução. Traduziu, entre outros autores, Boccaccio e Maquiavel, tendo recebido o Prêmio Jabuti, em 2003, pela tradução do Orlando Furioso de Ariosto. É paulista e reside na Capital de São Paulo. 